\title{
The urban built environment and overdose mortality in New York City neighborhoods
}

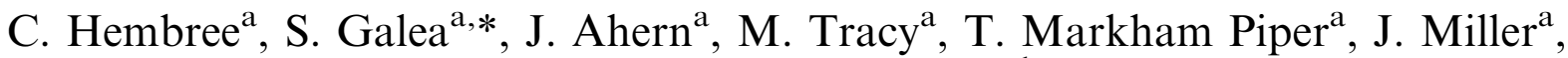 \\ D. Vlahov ${ }^{\mathrm{a}}$, K.J. Tardiff ${ }^{\mathrm{b}}$ \\ ${ }^{a}$ Center for Urban Epidemiologic Studies, New York Academy of Medicine, 1216 Fifth Avenue, New York, NY 100295293 , USA \\ ${ }^{\mathrm{b}}$ Department of Psychiatry, Weill Medical College of Cornell University, New York, NY 10021, USA
}

Accepted 10 February 2004

\begin{abstract}
Accidental drug overdose continues to be a substantial cause of mortality for drug users. Characteristics of the neighborhood built environment may be important determinants of the likelihood of drug overdose mortality independent of individual-level factors. Using data from the New York City Office of the Chief Medical Examiner, we conducted a multilevel case control study using data on accidental overdose deaths as cases and non-overdose accidental deaths as controls. We used archival data from the New York City Housing and Vacancy Survey and the Mayor's Office of Operations to assess characteristics of neighborhood external (e.g. dilapidation of buildings) and internal (e.g. quality of utilities in houses) built environment. Multilevel analyses were used to assess the relations between the neighborhood built environment and the likelihood of overdose death. Six out of the eight characteristics of the external environment studied and three out of the six characteristics of the internal environment studied were significantly associated with the likelihood of fatal drug overdose in multilevel models after adjusting for individuallevel (age, race, sex) and neighborhood-level (income, drug use) variables. Deterioration of the built environment, particularly the external environment, is associated with an increased likelihood of fatal accidental drug overdose. Disinvestment in social resources, psychosocial stressors, neighborhood differences in response to a witnessed overdose, and differences in vulnerability to the adverse consequences of drug use in different neighborhoods may explain the observed associations.
\end{abstract}

(C) 2004 Elsevier Ltd. All rights reserved.

Keywords: Overdose; Built environment; Physical environment; Urban health

\section{Introduction}

Despite decades of research and prevention efforts, drug use remains a primary source of morbidity and mortality in the US. According to the 2001 National Household Survey on Drug Abuse, 15.9 million or $7.1 \%$ of Americans were current users of illicit drugs in 2001 (National Household Survey of Drug Abuse, 2001) compared to $6.3 \%$ in 2000 (National Household Survey of Drug Abuse, 2000). Habitual drug users have an

\footnotetext{
*Tel.: + 1-212-822-7378; fax: + 1-212-876-6220

E-mail address: sgalea@nyam.org (S. Galea).
}

increased risk of morbidity and mortality and decreased life expectancy compared to non-drug users (McGinnis and Foege, 1999). Accidental drug overdose is a substantial cause of both morbidity and mortality among drug users (Joe and Simpson, 1987; Helpern, 1972; Cherubin et al., 1972; Bargagli et al., 2001; Oppenheimer et al., 1994; Hickman et al., 2003; Tyndall et al., 2001).

Several individual characteristics that are associated with drug use behavior have been identified, including for example, genetic susceptibility (Brown, 2002), parental drug use, low parental verbal reasoning skills, and childhood hyperactivity (Kaplow et al., 2002). 
However, much of the interpersonal variability in drug use and drug use risk behavior remains poorly understood (Darke et al., 1996). Recent work suggests that the traditional research focus on individual characteristics and behavior may be insufficient to fully account for inter-personal variability in drug use behavior and to allow for the development of interventions that can effectively curtail drug-related morbidity and mortality (Schmidt and McCarty, 2000).

Several researchers have noted that contextual influences affect the rate and severity of drug abuse within certain groups. Early work by Zinberg (1972) showed that soldiers had different levels of drug use depending upon location; most soldiers stationed in Vietnam had markedly decreased levels of addiction upon returning to the US. Boardman et al. (2001) hypothesized that stressful life events experienced by persons living in impoverished areas may be associated with abuse of drugs as a coping mechanism. Fitzpatrick and Gerard (1993) noted that community norms have an impact on drug use behaviors. Some work has also shown that drug overdose rates may be influenced by elements of the user's environment. Darke and Zador (1996) noted that contextual characteristics like the location of drug use activity, the presence of others, and the likelihood of others to call for help may affect rates of drug overdose. Marzuk et al. (1997) showed that poverty status accounted for $69 \%$ of the variance in fatal overdose rates between NYC neighborhoods. Galea et al. (2003) found an increase in rates of fatal accidental drug overdose among persons living in neighborhoods with high levels of income inequality.

Recently, there has been a growing interest in the built environment and its association with health (Krieger and Higgins, 2002; Handy et al., 2002; Cohen et al., 2003). For example, Weich et al. (2002) demonstrated higher levels of resident depression in areas that had less desirable built environments. Cohen et al. (2000) found that the prevalence of gonorrhea infection was higher in neighborhoods with deteriorating built environments in a study of New Orleans neighborhoods. However, the empiric relations between the built environment and substance use, overdose, and overdose death have seldom been investigated. Recent work has shown that characteristics of the built environment like liquor store distribution are disproportionately found in poor neighborhoods and are associated with higher levels of drug abuse (Donovan et al., 2002; LaVeist and Wallace, 2000; Weitzman et al., 2003). In light of the potential role of characteristics of the neighborhood environment as determinants of health and behavior, and in particular, of substance use and its consequences, we were interested in assessing the relation between characteristics of the built environment and the likelihood of drug overdose death. A priori we were interested in two different facets of the neighborhood built environment - the external (e.g. dilapidated buildings) and the internal (e.g. quality of utilities in houses) built environment.

\section{Methods}

All cases of fatal accidents occurring in adults aged 15-64 in NYC during 1996 were identified through manual review of medical files at the Office of the Chief Medical Examiner of New York (OCME). The OCME is responsible for assessing all deaths of persons believed to have died in an unnatural manner in NYC. Thus, all accidental deaths due to overdose and all accidental non-overdose deaths in NYC would have been reviewed by the OCME and included in this sample. The OCME investigators use the decedent's medical history, the circumstances and environment of the fatality (e.g., was the decedent found in a "shooting gallery"?), autopsy findings, and laboratory data to attribute cause of death and other criteria to each case reviewed. Deaths caused by accidental drug overdoses were considered cases in these analyses and deaths due to other accidents were considered controls. Non-overdose accidental deaths included in these analyses were poisoning, asphyxiation, drowning, firearm deaths, stabbing, electrocutions, blunt trauma, crushing, falls, vehicular accidents, burns, explosions, environmental exposures, and other accidents. Deaths caused by human intent are not considered accidents by the OCME and were not included in these analyses. Data regarding age, gender, race/ ethnicity, and residence were collected for all decedents from the OCME files.

NYC is divided into 59 residential community districts (CDs) by the Office of City Planning. These CDs delineate meaningful neighborhoods within NYC (Messner and Tardiff, 1986; Marzuk et al., 1997; Suecoff et al., 1999; Galea et al., 2003) and were used as neighborhood units in these analyses. These CDs will be referred to as neighborhoods hereafter. All cases and controls were geocoded to their neighborhood of residence. Decedents who resided outside NYC, did not have residential information or were classified as homeless were excluded from this analysis (there were no demographic differences between those included vs. excluded). We used 2000 US Census data to obtain median income in each neighborhood. All autopsied OCME cases undergo toxicological screening. We used proportion of accidental non-overdose decedents who were positive for any illegal drug other than marijuana to represent the level of drug use in a neighborhood (Galea et al., 2003).

Information on the structural characteristics of each neighborhood was collected from the 1999 New York City Housing and Vacancy Survey (NYCHVS) (US Census Bureau, 1999) and the Fiscal 2002 New York 
City Mayor's Management Report (New York City Mayor's Office of Operations. Fiscal, 2002). The NYCHVS is sponsored by the New York City Department of Housing Preservation and Development and has been conducted approximately every three years since 1962. The information is collected by trained field representatives who visit a sample of housing units in each neighborhood in NYC and complete a questionnaire via interview with one adult member of each unit. In 1999, about 15,500 occupied housing units were included in the NYCHVS; only occupied housing units were considered in these analyses in order to allow for comparison between the role of characteristics of the external and internal built environment. The median number of housing units sampled per neighborhood was 245 with a range of 187-702. The sub-borough areas used in the survey are the same as NYC neighborhoods in all but two areas in the Bronx and two in Manhattan, in which two neighborhoods were combined into one sub-borough. In these cases, the neighborhoods in question were assigned identical values from the corresponding sub-borough in our analyses.

The Mayor's Office of Operations compiles data from a number of New York City agencies including the New York City Fire Department and the Department of Sanitation, in the biannual Mayor's Management Report. Information from the fiscal year 2002 report, including data for each NYC neighborhood, was collected from the interactive 'My Neighborhood Statistics' feature on the Mayor's Management Report website and used in this analysis. This was mapped directly to neighborhoods so that no data manipulation was needed for our analyses.

Characteristics of the external and internal built environment used in these analyses are as described below.

\section{External built environment}

\section{Percent of buildings observed to be in dilapidated condition}

Percentage of buildings within each neighborhood that displayed one or more critical defects such as major open holes in the outside walls, or a number of intermediate defects, like missing stair railings, or poor original construction and thus incapable of providing safe and adequate shelter for occupants. This information was obtained from the NYCHVS.

\section{Percent of buildings observed to be in deteriorating condition}

Percentage of buildings within a neighborhood that displayed a lack of proper upkeep that could not be corrected by normal maintenance, demonstrated through one or more intermediate defects like rotted or loose window frames or broken or missing stair railings. This information was obtained from the NYCHVS.

Percent of buildings with any exterior wall problems

Percentage of buildings within a neighborhood that displayed one or more of the following characteristics: missing bricks, siding, or outside wall material, sloping or bulging outside walls, or major cracks in outside walls. This information was obtained from the NYCHVS.

\section{Percent of buildings with any window problems}

Percentage of buildings within a neighborhood that displayed one or more of the following characteristics: broken or missing windows, rotted or loose window frames or sashes, or boarded-up windows. This information was obtained from the NYCHVS.

\section{Percent of buildings with any exterior or interior stairway problems}

Percentage of buildings within a neighborhood that was determined to have one or more of the following characteristics: loose, broken or missing stair railways, or loose, broken, or missing steps. This information was obtained from the NYCHVS.

\section{Number of buildings experiencing structural fires}

Number of fire emergency incidents in each neighborhood to which the New York City Fire Department responded that were classified as structural fires, or fires that have spread throughout the structure of a building (in concealed spaces, between walls, along the roof, or outside of the building). This value does not include nonstructural fires (confined to the contents of a building, or outside, etc.), non-fire emergencies, medical emergencies, and malicious fire alarms. This information was obtained from the New York City Fire Department through the Mayor's Office of Operations.

\section{Percent of acceptably clean streets and sidewalks}

Percentage of streets and sidewalks in each neighborhood that met an acceptable standard of cleanliness based upon a seven point picture-based rating scale designed to reflect the public perception of acceptable cleanliness levels. This value is an annual average of twice monthly ratings of the city-wide street sample. This information was obtained from the Department of Sanitation from the Mayor's Office of Operations.

\section{Internal built environment}

\section{Percent of housing units experiencing toilet breakdowns}

Percentage of housing units within a neighborhood in which respondents experienced a time in the last three months in which all the toilets in the unit were not 
working for six consecutive hours. This information was obtained from the NYCHVS.

\section{Percent of housing units with some non-functioning kitchen facilities}

Percentage of housing units within a neighborhood in which respondents reported having one or more kitchen facilities that were not working at all. This information was obtained from the NYCHVS.

\section{Percent of housing units experiencing more than three heat breakdowns in winter}

Percentage of housing units within a neighborhood in which respondents experienced more than three breakdowns in heating equipment during the winter prior to the interview, during which time, heating equipment was completely unusable for six consecutive hours or longer. This information was obtained from the NYCHVS.

\section{Percent housing units needing additional heat in winter}

Percentage of housing units within a neighborhood in which respondents reported using additional sources of heat during the winter prior to the interview. Additional sources of heat included the kitchen stove, a fireplace, or a portable heater used at any time during the winter prior to the interview to supplement the regular system, because the regular system, though functioning, did not provide enough heat. This information was obtained from the NYCHVS.

\section{Percent housing units with large area peeling plaster or paint}

Percentage of housing units within a neighborhood that displayed an area of broken plaster or peeling paint on the interior ceiling or walls of larger than 8.5 by 11 in. This information was obtained from the NYCHVS.

\section{Percent housing units with water leakage inside}

Percentage of housing units within a neighborhood in which respondents reported experienced any water leaking into the unit in the last 12 months, not including leaks that resulted from the unit's own plumbing fixtures backing up or overflowing. This information was obtained from the NYCHVS.

\section{Statistical analysis}

We described the overdose and accident death rates by neighborhood and used chi-square tests and $t$-tests as appropriate to test for differences between demographic factors in cases and controls. Crude mortality rates were calculated for each neighborhood as the number of fatal drug overdoses and the number of fatal accidents per 100,000 residents per neighborhood using 2000 US Census population estimates of the neighborhood populations (US Census Bureau, 2000). We assessed the ecologic association between each characteristic of the neighborhood environment, overdose, and accident mortality rates using parametric and non-parametric models to describe best-fit statistical models. We constructed multilevel hierarchical models that assessed the relation between each characteristic of the built environment and the likelihood of overdose death. We used separate multilevel models for each characteristic of the built environment (total 14 unadjusted and 14 adjusted models). In an attempt to avoid possible confounding, neighborhood level of drug use (obtained from OCME files), median neighborhood income in 2000 (obtained from the US Census) and demographic characteristics of decedents (age, gender, race and ethnicity obtained from OCME reports) were controlled for in the final analyses.

\section{Results}

Table 1 presents baseline demographics of the study sample. There were 725 accidental drug overdose deaths and 453 non-overdose accidental deaths reported in OCME files from 1996. Decedents included in the sample were between the ages of 15 and 64 . Forty-three percent $(43 \%)$ of deaths due to accidental overdose were among those between the ages of 35 and 44 compared with $21.2 \%$ in the accidental non-overdose decedents. Accidental overdose decedents and accidental nonoverdose decedents both were predominantly men ( $76.3 \%$ and $78.8 \%$, respectively). Accidental overdose decedents were $32.1 \%$ White, $37.2 \%$ Black, and $29.7 \%$ Hispanic; accidental non-overdose decedents were $29.8 \%$ White, $33.5 \%$ Black, and $28.5 \%$ Hispanic. Median neighborhood income was $\$ 34,785$ dollars for accidental overdose decedents and $\$ 36,997$ for accidental non-overdose decedents.

We assessed the ecologic associations between each characteristic of the external and internal built environments and neighborhood overdose and accident mortality rates. For the purpose of illustration we included two graphs of the associations between mortality rates and two selected characteristics of the external and internal environment.

Fig. 1 demonstrates the association between the percent of buildings in the neighborhood with any window problems (a characteristic of the external built environment), and death due to overdose or accident per 100,000 person-years. The figure shows best-fit nonparametric spline models demonstrating that while both the overdose and accident death rates increase as the percent of buildings in their area of residence with any window problems increases, the rate of increase is greater for accidental drug overdose death than for accidental non-overdose death. 
Table 1

Baseline demographics of the study sample

\begin{tabular}{|c|c|c|c|c|c|}
\hline & \multicolumn{2}{|l|}{ Overdose deaths } & \multicolumn{2}{|c|}{ Accident deaths } & \multirow[t]{3}{*}{$p$-Value ${ }^{\mathrm{a}}$} \\
\hline & \multicolumn{2}{|l|}{$N=725$} & \multicolumn{2}{|c|}{$N=453$} & \\
\hline & $N$ & $\%$ & $N$ & $\%$ & \\
\hline \multicolumn{6}{|l|}{ Characteristics of decedents } \\
\hline \multicolumn{6}{|l|}{ Age } \\
\hline $15-24$ & 34 & 4.7 & 64 & 14.1 & $<0.001$ \\
\hline $25-34$ & 147 & 20.3 & 101 & 22.3 & \\
\hline $35-44$ & 312 & 43.0 & 96 & 21.2 & \\
\hline $45-54$ & 196 & 27.0 & 104 & 23.0 & \\
\hline $55-64$ & 36 & 5.0 & 88 & 19.4 & \\
\hline Mean age (SD) & $40.4(8.7)$ & $40.6(13.5)$ & & & 0.69 \\
\hline \multicolumn{6}{|l|}{ Gender } \\
\hline Male & 553 & 76.3 & 357 & 78.8 & 0.31 \\
\hline Female & 172 & 23.7 & 96 & 21.2 & \\
\hline \multicolumn{6}{|l|}{ Race/ethnicity } \\
\hline White & 233 & 32.1 & 135 & 29.8 & $<0.001$ \\
\hline Black & 270 & 37.2 & 152 & 33.5 & \\
\hline Hispanic & 215 & 29.7 & 129 & 28.5 & \\
\hline \multirow[t]{2}{*}{ Other } & 7 & 1.0 & 37 & 8.2 & \\
\hline & Mean & SD & Mean & $\mathrm{SD}$ & \\
\hline \multicolumn{6}{|l|}{ Characteristics of neighborhoods where decedents lived } \\
\hline Mean median income (SD) & $\$ 34,785(\$ 14,839)$ & $\$ 36,997(\$ 13,992)$ & & & 0.01 \\
\hline Prevalence of drug misuse $(\mathrm{SD})^{\mathrm{b}}$ & $26.4(19.9)$ & $21.0(18.5)$ & & & $<0.001$ \\
\hline \multicolumn{6}{|l|}{ External physical environment } \\
\hline Percent of buildings observed to be in dilapidated condition & 1.3 & 1.8 & 1.0 & 1.4 & 0.002 \\
\hline Percent of buildings observed to be in deteriorating condition & 6.8 & 4.2 & 6.1 & 3.8 & 0.006 \\
\hline Percent of buildings with any external wall problems & 3.6 & 3.5 & 3.2 & 3.1 & 0.05 \\
\hline Percent of buildings with any window problems & 3.9 & 3.1 & 3.3 & 2.7 & $<0.001$ \\
\hline $\begin{array}{l}\text { Percent of buildings with any exterior or interior stairway } \\
\text { problems }\end{array}$ & 6.1 & 4.7 & 5.2 & 4.2 & $<0.001$ \\
\hline Number of structural fires & 517.8 & 197.7 & 477.0 & 189.7 & $<0.001$ \\
\hline Percent of acceptably clean streets & 78.1 & 7.9 & 79.6 & 8.1 & 0.001 \\
\hline Percent of acceptably clean sidewalks & 86.3 & 7.9 & 87.5 & 7.4 & 0.01 \\
\hline \multicolumn{6}{|l|}{ Internal physical environment } \\
\hline Percent of housing units experiencing toilet breakdowns & 10.5 & 3.9 & 9.6 & 3.7 & $<0.001$ \\
\hline $\begin{array}{l}\text { Percent of housing units with some non-functioning kitchen } \\
\text { facilities }\end{array}$ & 2.7 & 1.4 & 2.5 & 1.4 & 0.02 \\
\hline $\begin{array}{l}\text { Percent of housing units experiencing over three heat } \\
\text { breakdowns in winter }\end{array}$ & 5.5 & 4.3 & 4.7 & 3.7 & $<0.001$ \\
\hline Percent of housing units needing additional heating in winter & 12.9 & 6.6 & 11.5 & 5.8 & $<0.001$ \\
\hline $\begin{array}{l}\text { Percent of housing units with a large area of peeling plaster or } \\
\text { paint }\end{array}$ & 7.4 & 3.5 & 6.6 & 3.6 & $<0.001$ \\
\hline Percent of housing units with internal water leakage & 17.4 & 5.9 & 16.8 & 6.0 & 0.06 \\
\hline
\end{tabular}

${ }^{\mathrm{a}}$ Two tailed $\chi^{2}$ and $t$-test $p$-values as appropriate.

${ }^{\mathrm{b}}$ Mean percent of accidents with drugs detected per neighborhood.

Fig. 2 demonstrates the association between the percent of occupied housing units in the neighborhood needing additional heating during winter (a characteristic of the internal built environment), and rate of death due to overdose or accident per 100,000 person-years. The figure shows that while both the overdose and accident death rates increase as the percent of occupied housing units needing additional heating during winter 


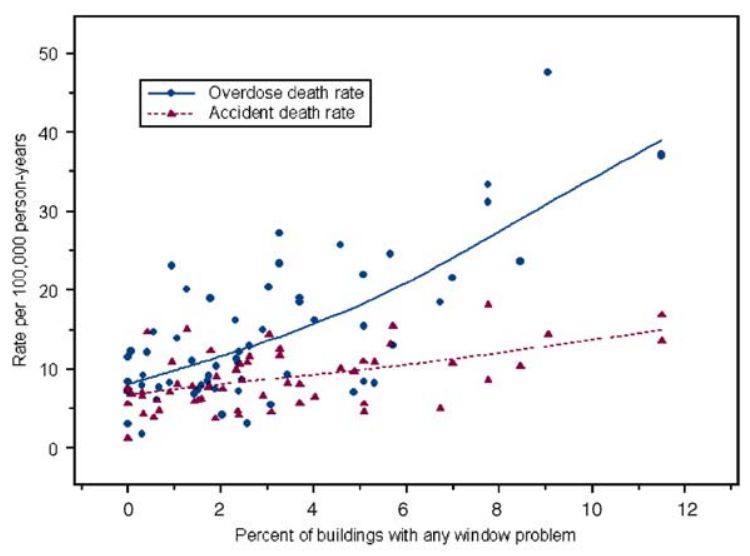

Fig. 1. Best-fit spline models demonstrating the association between a characteristic of the external built environment (the percent of buildings with any window problem), and death due to overdose or accident per 100,000 person-years in New York City Community Districts.

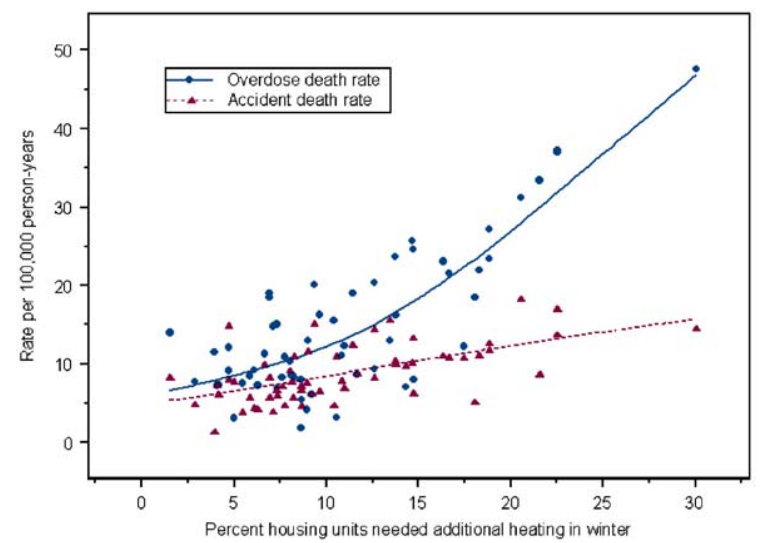

Fig. 2. Best-fit spline model demonstrating the association between a characteristic of the internal built environment (the percent of housing units needing additional heat in winter), and death due to overdose or accident per 100,000 person-years in New York City Community Districts.

increases, the rate of increase is greater for accidental drug overdose than for accidental non-overdose death.

Table 2 shows the bivariate and the multivariate relations between neighborhood level characteristics and likelihood of drug overdose death. In separate multilevel logistic regression analyses adjusting for neighborhood drug use, median household income, and demographics, the characteristics of the external built environment that were significantly associated with a higher likelihood of drug overdose death were percent of buildings found to be in dilapidated conditions $(p<.001)$, percent of buildings with any window problems $(p=0.04)$, percent of buildings with any exterior or interior stairway problems $(p=0.004)$, percent of buildings observed to be in deteriorating condition $(p=0.05)$, number of structural fires $(p=0.01)$, and percent of acceptably clean streets $(p=0.04)$. Of the characteristics of the internal built environment, percent of housing units experiencing toilet breakdowns $(p=0.03)$, percent of housing units needing additional heating in winter $(p<0.001)$ and percent of housing units with large areas of peeling plaster or paint $(p=0.04)$ were significantly associated with a higher likelihood of drug overdose death in separate multilevel multivariate models.

\section{Discussion}

We demonstrated an association between characteristics of the neighborhood built environment and the likelihood of accidental drug overdose death in NYC neighborhoods in models controlling for individual-level (age, race, sex) and neighborhood-level (income, drug use) variables. Drug overdose was a more likely cause of accidental death in neighborhoods with a deteriorating external environment than in neighborhoods where the external built environment was not deteriorating; this association was robust over six out of eight characteristics of the external built environment. This relation was also present between three of the six characteristics of the internal built environment studied and the likelihood of accidental drug overdose death.

The results of this study are consistent with work that has demonstrated associations between the deterioration of the built environment and poor health outcomes. For example, Cohen et al. $(2000,2003)$ demonstrated that residents in neighborhoods with more boarded-up housing were more likely to have gonorrheal infections, all-cause premature mortality, and premature mortality due to malignant neoplasm, diabetes, homicide and suicide after controlling for individual level factors. Cummins and Jackson (2001) have suggested that the increase of obesity in American children is secondary to fewer opportunities for exercise just as the rise in asthma rates are a result of escalating levels of environmental air pollutants, both of which may relate to aspects of the built environment. Wallace and Wallace (1988) demonstrated a relation, through mathematical modeling, between the deterioration of infrastructure in NYC as a whole and the rise in drug abuse within the Bronx.

There are a number of factors associated with neighborhood deterioration that probably influence the likelihood of drug overdose mortality and, as such, a number of hypotheses may explain the observed association between characteristics of the built environment and likelihood of drug overdose. First, it is possible that the deteriorating built environment is a proxy for a lack of empowerment and collective efficacy 
Table 2

Bivariate and multivariate relations between characteristics of the built environment and likelihood of drug overdose death ${ }^{\mathrm{a}}$

\begin{tabular}{|c|c|c|c|c|c|c|c|c|c|c|c|}
\hline & \multirow[t]{2}{*}{ Parameter } & \multicolumn{5}{|c|}{ Unadjusted } & \multicolumn{5}{|c|}{$\begin{array}{l}\text { Adjusted for neighborhood drug use, median } \\
\text { household income, age, sex, and race }\end{array}$} \\
\hline & & Estimate & $\mathrm{SE}$ & Low CI & High CI & $p$-Value & Estimate & SE & Low CI & High CI & $p$-Value \\
\hline & $\begin{array}{l}\text { Percent of buildings observed to be in dilapidated } \\
\text { condition }\end{array}$ & 0.12 & 0.03 & 0.06 & 0.17 & $<0.0001$ & 0.08 & 0.02 & 0.04 & 0.11 & $<0.001$ \\
\hline & $\begin{array}{l}\text { Percent of buildings observed to be in deteriorating } \\
\text { condition }\end{array}$ & 0.04 & 0.02 & 0.007 & 0.07 & 0.02 & 0.03 & 0.016 & -0.0001 & 0.06 & 0.05 \\
\hline External & $\begin{array}{l}\text { Percent of buildings with any external wall } \\
\text { problem }\end{array}$ & 0.03 & 0.02 & -0.001 & 0.07 & 0.06 & 0.01 & 0.02 & -0.03 & 0.05 & 0.56 \\
\hline Built & $\begin{array}{l}\text { Percent of buildings with any window } \\
\text { problem }\end{array}$ & 0.07 & 0.02 & 0.03 & 0.11 & $<0.001$ & 0.05 & 0.03 & 0.003 & 0.10 & 0.04 \\
\hline \multirow[t]{5}{*}{ Environment } & $\begin{array}{l}\text { Percent of buildings with any exterior or interior stairway } \\
\text { problem }\end{array}$ & 0.04 & 0.01 & 0.02 & 0.07 & $<0.001$ & 0.04 & 0.01 & 0.013 & 0.07 & 0.004 \\
\hline & Number of structural fires & 0.001 & 0.0003 & 0.0005 & 0.002 & $<0.001$ & 0.0007 & 0.0003 & 0.0001 & 0.001 & 0.01 \\
\hline & Percent acceptably clean streets & -0.02 & 0.01 & -0.04 & -0.009 & 0.002 & -0.02 & 0.009 & -0.04 & -0.0008 & 0.04 \\
\hline & Percent acceptably clean sidewalks & -0.02 & 0.01 & -0.04 & -0.005 & 0.008 & -0.02 & 0.01 & -0.04 & 0.005 & 0.12 \\
\hline & Percent housing units experienced toilet breakdown & 0.06 & 0.01 & 0.03 & 0.09 & $<0.001$ & 0.04 & 0.02 & 0.005 & 0.08 & 0.03 \\
\hline Internal & $\begin{array}{l}\text { Percent housing units with some non-functioning kitchen } \\
\text { facilities }\end{array}$ & 0.10 & 0.04 & 0.02 & 0.18 & 0.02 & 0.04 & 0.05 & -0.05 & 0.13 & 0.36 \\
\hline Built & $\begin{array}{l}\text { Percent housing units experienced }>3 \text { heat breakdowns in } \\
\text { winter }\end{array}$ & 0.05 & 0.01 & 0.03 & 0.07 & $<0.001$ & 0.03 & 0.02 & -0.004 & 0.07 & 0.08 \\
\hline \multirow[t]{3}{*}{ Environment } & Percent housing units needed additional heating in winter & 0.03 & 0.01 & 0.02 & 0.05 & $<0.001$ & 0.04 & 0.01 & 0.01 & 0.06 & $<0.001$ \\
\hline & Percent housing units with large area peeling plaster/paint & 0.06 & 0.02 & 0.03 & 0.10 & $<0.001$ & 0.05 & 0.02 & 0.003 & 0.10 & 0.04 \\
\hline & Percent housing units with water leakage inside & 0.02 & 0.01 & -0.003 & 0.04 & 0.10 & 0.001 & 0.01 & -0.02 & 0.02 & 0.89 \\
\hline
\end{tabular}

${ }^{\text {a }}$ Separate models for each of the characteristics of the external and the internal built environment; total 14 unadjusted and 14 adjusted models. 
in urban neighborhoods. Sampson et al. (1997) noted that neighborhood collective efficacy can shape the built environment as neighborhoods with high collective efficacy can better extract resources and respond to reductions in public services (such as police patrols, fire stations, garbage collection, and housing code enforcement) and monitor activity like spray-painting of graffiti on local buildings. Therefore, neighborhoods with positive built environments may have higher collective efficacy which in turn can be associated with less drug use behavior or safer drug using practices. Consistent with this hypothesis, Longshore et al. (1996) found that among black and Latino injection drug users, higher levels of perceived group efficacy resulted in the adoption of healthier behavior associated with their drug use.

Second, living in a deteriorating built environment can lead to different patterns of drug use behavior. Psychological distress in residents in neighborhoods with deteriorating built environment may encourage greater risk taking and more dangerous drug abuse behavior. Weich et al. (2002) found that persons living in a neighborhood with external markers of deterioration (such as abundant graffiti and structural housing problems) had a greater likelihood of depression. Perdue et al. (2003) demonstrated that injection drug users who were depressed were more likely to engage in risky injection practices. Thus drug users in neighborhoods with deteriorating external environments may be more likely to engage in risky drug use practices which may predispose them to a higher likelihood of overdose and potential accidental drug overdose mortality.

Third, it is possible that the relation between a deteriorating built environment and overdose death could be explained by different behaviors of persons who witness overdoses in neighborhoods characterized by different physical conditions. Zador et al. (1996) found that in fatal overdose cases, an ambulance was called only $10 \%$ of the time while the person who had overdosed was still alive. As previously noted, residence in a deteriorating built environment has been associated with decreased levels of collective efficacy (Sampson et al., 1997). Collective efficacy encompasses willingness of neighbors to intervene if they witness deviant behavior. It is plausible then that residents of neighborhoods with low collective efficacy may also be less likely to intervene if they witness someone overdose, either in terms of offering first aid or activating the emergency medical system. It also is worth noting the markedly higher prevalence of incarceration among persons living in disadvantaged urban communities which are also typically neighborhoods with a deteriorating built environment (Freudenberg, 2001). It is possible that fear of incarceration (i.e., if police arrive on the scene after the emergency medical system is activated) among those in disadvantaged communities may contribute to a lower likelihood of activating the emergency medical system and a greater likelihood of fatal overdose in these neighborhoods.

Fourth, persons living in areas with deteriorating built environments may have worse baseline health than those living in better neighborhoods. Studies have documented poorer health in neighborhoods with poorer built environments (Krieger and Higgins, 2002; Cohen et al., 2003). It is possible that residents of neighborhoods with deteriorating physical characteristics are more vulnerable to fatal overdose in conjunction with drug use.

We assessed differences between the role of the external physical built environment and the internal built environment by individually testing several characteristics of each. We found that characteristics of a deteriorating external built environment were more consistently associated with greater likelihood of accidental fatal drug overdose than were characteristics of the internal built environment. The majority of the published peer-reviewed literature about the relation between the built environment and health has focused upon characteristics of the external built environment (Cohen et al., 2003; Weich et al., 2002). Many of our hypothesized explanations would predict a strong relation between the external built environment and drug overdose. Collective efficacy is more likely to affect shared neighborhood spaces, which are mostly external. Unwillingness to call for help, which is related to collective efficacy, is more likely to be associated with external characteristics of deterioration. Both internal and external characteristics may be responsible for increased levels of psychological distress in residents of deteriorating environments. As few researchers have compared the role of the external and the internal built environment, we cannot be sure that one has not served as a proxy for the other in previous studies. Clearly the association between the built environment and drug overdose is complicated. We suggest that further research is indicated to clarify which characteristics of the built environment may be associated with specific morbidities and risk behaviors, including drug use and its consequences.

There were a number of limitations in this study. We were limited by the cross-sectional study design. Although drug overdose is plausibly affected by recent neighborhood conditions, we did not have information on how long decedents had lived in their neighborhoods or how their neighborhoods had changed while they were living there. Our analysis made use of existing data and as such we were limited by the years in which the studies utilized were conducted. Our outcome data was obtained in 1996 while our data on the state of the built environment was from 1999 and 2001. Neighborhoods do not change quickly (Geronimus et al., 1999), thus we expect our data, collected in the same five year period, to be a reasonable approximation of a cross-sectional data 
set. Accident decedents have been shown to have a higher rate of drug use than the general population (Bastos and Galante, 1976) and it is plausible that our control group has a higher rate of drug use than the general population. This may introduce a bias toward the null, and, as such, our documentation of a relation between characteristics of the built environment and likelihood of overdose suggests that our results may be an underestimate of the true relation between characteristics of the neighborhood built environment and drug overdose death. Although we adjusted for individual age, race and gender, data on individual socioeconomic status was not available; individual socioeconomic status may be associated with neighborhood characteristics and risk of overdose death, so this omission may lead to an overestimate of the neighborhood effects. It is also possible that OCME determination of cause of death was influenced by knowledge of neighborhood where the overdose occurred. A systematic bias in OCME reporting whereby deaths in neighborhoods with deteriorating built environment are more likely to be attributed to accidental drug overdose may result in a bias away from the null. Ultimately, although we controlled for neighborhood drug use, we had no information on the amount of drug used by individuals in this study. We also note that these observations, based on fatal accidental drug overdoses, cannot be generalized to non-fatal overdoses. With respect to our assessment of the built environment, we included only assessments about the external and internal characteristics of occupied housing units to allow for comparison between the two features of the built environment. Given that the external characteristics of vacant properties are likely to be worse than those of occupied properties, it is likely that we present here a conservative assessment of the relation between features of the external built environment and the risk of overdose.

Notwithstanding these limitations, this study showed that characteristics of the built environment are associated with likelihood of fatal accidental drug overdose independent of individual-level and other neighborhood-level factors. Further work is needed in order to understand the mechanism that explains the observed relations between the built environment and risk of fatal drug overdose. This study adds to the growing literature which suggests the importance of the built environment in shaping health and behavior. The rapid pace of urbanization globally (Vlahov and Galea, 2002), and the potential role that the built environment may play in shaping health and behavior (Northridge and Sclar, 2003), call for increased collaboration between urban planning and public health professionals in order to identify how the health of those living in deteriorating urban built environments can be improved.

\section{References}

Bargagli, A.M., Sperati, A., Davoli, M., Forastiere, F., Perucci, C.A., 2001. Mortality among problem drug users in Rome: An 18-year follow-up study, 1980-97. Addiction 96 (10), 1455-1463.

Bastos, M.L., Galante, L., 1976. Toxicological findings in victims of traumatic deaths. Journal of Forensic Sciences 21 (1), 176-186.

Boardman, J.D., Finch, B.K., Ellison, C.G., Williams, D.R., Jackson, J.S., 2001. Neighborhood disadvantage, stress, and drug use among adults. Journal of Health and Social Behavior 42 (2), 151-165.

Brown, R.T., 2002. Risk factors for substance abuse in adolescents. Pediatric Clinics of North America 49 (2), 247-255.

Cherubin, C., McCusker, J., Baden, M., Kavaler, F., Amsel, Z., 1972. Epidemiology of death in narcotic addicts. American Journal of Epidemiology 96 (1), 11-22.

Cohen, D.A., Spear, S., Scribner, R., Kissinger, P., Mason, K., Wildgen, J., 2000. Broken windows and the risk of gonorrhea. American Journal of Public Health 90 (2), 230-236.

Cohen, D.A., Mason, K., Bedimo, A., Scribner, R., Basolo, V., Farley, T.A., 2003. Neighborhood physical conditions and health. American Journal of Public Health 93 (3), 467-471.

Cummins, S.K., Jackson, R.J., 2001. The built environment and children's health. Pediatric Clinics of North America 48 (5), 1241-1250.

Darke, S., Zador, D., 1996. Fatal heroin 'overdose': a review. Addiction 91 (12), 1765-1772.

Darke, S., Ross, J., Hall, W., 1996. Overdose among heroin users in Sidney, Australia: I. prevalence and correlates of non-fatal overdose. Addiction 91 (3), 405-411.

Donovan, R.J., Jancey, J., Jones, S., 2002. Tobacco point of sale advertising increases positive brand user imagery. Tobacco Control 11 (3), 191-194.

Fitzpatrick, J.L., Gerard, K., 1993. Community attitudes towards drug use: the need to assess community norms. The International Journal of the Addictions 28 (10), 947-957.

Freudenberg, N., 2001. Jails, prisons, and the health of urban populations: a review of the impact of the correctional system on community health. Journal of Urban Health 78 (2), 214-235.

Galea, S., Ahern, J., Vlahov, D., Coffin, P., Fuller, C., Leon, A., Tardiff, K., 2003. Income distribution and risk of fatal drug overdose in NYC neighborhoods. Drug and Alcohol Dependence 70 (2), 139-148.

Geronimus, A.T., Bound, J., Waidmann, T.A., 1999. Health inequality and population variation in fertility-timing. Social Science and Medicine 49 (12), 1623-1636.

Handy, S.L., Boarnet, M.G., Ewing, R., Killingsworth, R.E., 2002. How the built Environment affects physical activity, views from urban planning. American Journal of Preventative Medicine 23 (2S), 64-73.

Helpern, M., 1972. Fatalities from narcotic addiction in New York City. Human Pathology 3, 13-21.

Hickman, M., Madden, P., Henry, J., Baker, A., Wallace, C., Wakefield, J., Stimson, G., Elliott, P., 2003. Trends in drug overdose deaths in England and Wales 1993-98: methadone 
does not kill more people than heroin. Addiction 98 (4), 419-425.

Joe, G.W., Simpson, D.D., 1987. Mortality rates among opioid addicts in a longitudinal study. American Journal of Public Health 77, 347-348.

Kaplow, J.B., Curran, P.J., Dodge, K.A., 2002. The conduct problems prevention research group: child, parent, and peer predictors of early onset substance use: a multisite longitudinal study. Journal of Abnormal Child Psychology 30 (3), 199-216.

Krieger, J., Higgins, D.L., 2002. Housing and health: time again for public health action. American Journal of Public Health 92 (5), 758-768.

LaVeist, T.A., Wallace, J.M., 2000. Health risk and inequitable distribution of liquor stores in African American neighborhood. Social Science and Medicine 51 (4), 613-617.

Longshore, D., Stein, J., Anglin, M., 1996. Ethnic differences in the psychosocial antecedents of needle/syringe disinfection. Drug and Alcohol Dependence 42 (3), 183-196.

Marzuk, P., Tardiff, K., Leon, A.C., Hirsch, C.S., Stajic, M., Portera, L., Hartwell, N., 1997. Poverty and fatal accidental drug overdoses of cocaine and opiates in New York City: an ecological study. American Journal of Drug and Alcohol Abuse 23 (2), 221.

McGinnis, J.M., Foege, W.H., 1999. Mortality and morbidity attributable to use of addictive substances in the United States. Proceedings of the Association of American Physicians 111, 109-118.

Messner, S.F., Tardiff, K., 1986. Economic inequality and levels of homicide: an analysis of urban neighborhoods. Criminology 24, 297-317.

National Household Survey on Drug Abuse, 2000. Substance Abuse and Mental Health Serivce Administration. Available at: http://www.samhsa.gov/oas/NHSDA/1997Main?Table $\% 20$ of $\% 20$ Contents.htm. Accessed in June of 2003.

National Household Survey on Drug Abuse, 2001. Substance Abuse and Mental Health Serivce Administration. Available at: http://www.samhsa.gov/oas/NHSDA/1997Main?Table $\% 20$ of $\% 20$ Contents.htm. Accessed in June of 2003.

New York City Mayor's Office of Operations. Fiscal, 2002. Mayor's Management Report. Available at http://www.nyc. gov $/ \mathrm{mmr}$.

Northridge, M.E., Sclar, E., 2003. A joint urban planning and public health framework: contributions to health impact assessment. American Journal of Public Health 93, $118-121$.
Oppenheimer, E., Tobutt, C., Taylor, C., Andrew, T., 1994. Death and survival in a cohort of heroin addicts from London clinics: a 22 year follow-up. Addiction 89, 1299-1308.

Perdue, T., Hagan, H., Thiede, H., Valleroy, L., 2003. Depression and HIV risk behavior among Seattle-area injection drug users and young men who have sex with men. AIDS Education and Prevention 15 (1), 81-92.

Sampson, R.J., Raudenbush, S., Earls, F., 1997. Neighborhoods and violent crime: a multilevel study of collective efficacy. Science 277 (5328), 918-924.

Schmidt, L.A., McCarty, D., 2000. Welfare reform and the changing landscape of substance abuse services for lowincome women. Alcoholism 24 (8), 1298-1311.

Suecoff, S.A., Avner, J.R., Chou, K.J., Crain, E.F., 1999. A comparison of New York City playground hazards in highand low-income areas. Archives of Pediatrics and Adolescent Medicine 153 (4), 363-366.

Tyndall, M.W., Craib, K.J., Currie, S., Li, K., O'Shaughnessy, M.V., Schechter, M.T., 2001. Impact of HIV infection on mortality in a cohort of injection drug users. Journal of Acquired Immune Deficiency Syndromes 28 (4), 351-357.

US Census Bureau, 1999. New York City Housing and Vacancy Survey, available at http://landview.census.gov/ hhes/www/nychvs.html.

US Census Bureau, 2000. Census summary tape, file 3A (STF3A). Washington, DC: US Dept of Commerce, 2000.

Vlahov, D., Galea, S., 2002. Urbanization, urbanicicty, and health. Journal of Urban Health 79 (4 Suppl 1), S1-S12.

Wallace, R., Wallace, 1998. A Plague on Your Houses: How New York was Burned Down and National Public Health Crumbled. Verso, New York.

Weich, S., Blanchard, M., Prince, M., Burton, E., Erens, B., Sproston, K., 2002. Mental health and the built environment: cross-sectional survey of individual and contextual risk factors for depression. The British Journal of Psychiatry $180,428-433$

Weitzman, E.R., Folman, A., Lemieux Folkman, K., Wechsler, H., 2003. The relationship of alcohol outlet density to heavy and frequent drinking and drinking-related problems among college students at eight universities. Health and Place 9, 1-6.

Zador, D., Sunjic, S., Darke, S., 1996. Heroin-related deaths in New South Wales, 1992: toxicological findings and circumstances. Medical Journal of Australia 164 (4), 204-207.

Zinberg, N.E., 1972. Drugs and the Public. Simon and Schuster, New York. 